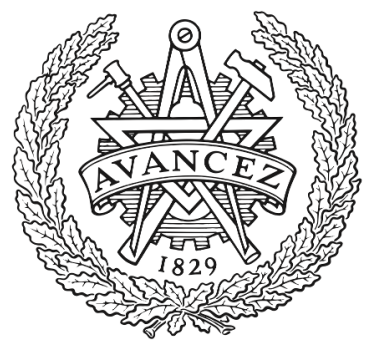

CHALMERS

UNIVERSITY OF TECHNOLOGY

\title{
Large-scale introduction of forest-based biorefineries: Actor perspectives and the impacts of a dynamic biomass market
}

Downloaded from: https://research.chalmers.se, 2023-04-26 07:44 UTC

Citation for the original published paper (version of record):

Zetterholm, J., Ahlström, J., Bryngemark, E. (2020). Large-scale introduction of forest-based biorefineries: Actor perspectives and the impacts of a dynamic biomass market. Biomass and Bioenergy, 142.

http://dx.doi.org/10.1016/j.biombioe.2020.105782

N.B. When citing this work, cite the original published paper. 


\title{
Large-scale introduction of forest-based biorefineries: Actor perspectives and the impacts of a dynamic biomass market
}

\author{
Jonas Zetterholm ${ }^{\mathrm{a}, *}$, Johan Ahlström ${ }^{\mathrm{b}}$, Elina Bryngemark ${ }^{\mathrm{c}}$

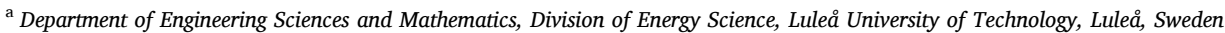 \\ ${ }^{\mathrm{b}}$ Department of Space, Earth and Environment, Division of Energy Technology, Chalmers University of Technology, Gothenburg, Sweden \\ ${ }^{c}$ Department of Business Administration, Technology and Social Science, Luleå University of Technology, Sweden
}

\section{A R T I C L E I N F O}

\section{Keywords:}

Price formation

Supply chain

Policymaker

Plant-owner

Biofuel

Large-scale

\begin{abstract}
A B S T R A C T
Large-scale implementation of forest-based biofuel production will have an impact on biomass prices, something which in turn will affect biofuel production costs. The profitability of emerging biofuel production technologies is usually assessed using techno-economic or market approaches. While techno-economic approaches have a detailed description of technologies within plant-level or supply chain system boundaries, they build on exogenously given static biomass prices. Conversely, market approaches have a consistent description of the economic system including market interactions for prices within local or national boundaries, but they generally lack technological depth. This paper combines these two approaches using an iterative framework for a case study optimising the production cost of liquefied biomethane (LBG) using different configurations of sawmillintegrated biomass gasification.

Cost estimates are developed using system boundaries surrounding a LBG production plant, and the Swedish national borders, reflecting the plant-owner and policymaker perspectives, respectively. The results show that different plant configurations are favoured depending on the choice between minimising the biofuel production cost for the plant-owner or for the policymaker. Market dynamics simulated by the iterative procedure show that a direct policy support of 36-56 EUR/MWh would be needed to sustain large-scale LBG production, which is $12-31 \%$ higher than the necessary policy support estimated based on static biomass prices.
\end{abstract}

\section{Introduction}

Producing bio-synthetic natural gas (Bio-SNG) by gasification of forest residues is an economically viable option for manufacturing biofuels with high efficiency [1]. The economic case is enhanced further if Bio-SNG production is feedstock and heat-integrated with a sawmill [2-4]. Bio-SNG can be liquefied to produce liquefied biomethane (LBG), which can directly replace liquefied natural gas (LNG) in transport and heavy industry in areas without a gas grid [2].

Investments in large-scale forest-based biofuel production have been rare, partly explained by uncertainties in future market prices, policy support, and technology costs [5-7]. These factors reduce investment likelihood as low-risk projects are preferred $[8,9]$. Of particular importance is biomass cost risk $[1,8]$, which can constitute $10-28 \%$ of forest-based biofuel production cost [7].

Partial equilibrium modelling simulations have shown that largescale implementation of biofuel production is likely to affect feedstock prices and resource allocation, e.g. [10,11]. In a Nordic context, biomass prices could increase with up to $35 \%$ [12]. With new biomass prices, industry profitability is likely to change. Modelling studies have shown that large-scale forest-based biofuel production is likely to result in decreased profitability in the pulp industry due to increased pulpwood prices, and increased profitability in the sawmill industry due to increased demand for their by-products $[11,13]$. The specific biomass assortment used as feedstock for biofuel production will influence which industries benefit or lose from the implementation of biofuel production [14].

To identify the performance of a biofuel supply chain, models that minimise the total system cost are often applied, see e.g. [15-17]. Uncertain price developments are sometimes accounted for by price sensitivity analyses, scenarios with systematic assumptions regarding the surrounding system [18], or stochastic price processes to simulate future prices [19]. However, these approaches do not consider the price dynamics caused by the change under evaluation, e.g. impact on biomass prices from the introduction of large-scale forest-based biofuel

\footnotetext{
* Corresponding author.

E-mail addresses: jonas.zetterholm@ltu.se (J. Zetterholm), johanah@chalmers.se (J. Ahlström), johanah@chalmers.se (E. Bryngemark).
} 


\begin{tabular}{|llll|}
\hline Nomenclature & LNG & Liquefied natural gas \\
& & MILP & Mixed integer linear programming \\
BF & Biofuel & $O \& M$ & Operation and maintenance \\
$c r f$ & Capital recovery factor & $P_{d e p, t r i}$ & Distance dependent transport cost of commodity $i$ \\
CHP & Combined heat and power & $P_{f i x, t r i}$ & Fixed transport cost of commodity $i$ \\
DH & District heat & $P_{i}$ & Price of commodity $i$ \\
$D P C$ & Direct production cost & $P_{L N G}$ & Price of liquefied natural gas \\
$D S C$ & Direct supply cost & $P S C_{\text {direct }}$ Direct policy support cost \\
$d_{t r, i}$ & Transport distance of commodity $i$ & $P S C_{\text {indirect }}$ Indirect policy support cost \\
$E_{i}$ & Input/output of commodity $i$ & $P_{t r, i}$ & Transport cost of commodity $i$ \\
$I$ & Investment cost & SNG & Synthetic natural gas \\
$i$ & Commodity index & Syscost & Total system cost \\
$j$ & Facility index & TSSC & Total system supply cost \\
LBG & Liquefied biomethane & & \\
\hline
\end{tabular}

production.

The strengths of a detailed technology representation in energy system models and the market representation and development in partial or general equilibrium models have previously been combined by using soft-linking, see for example [20-23]. Due to these strengths, soft-linking has often been applied in climate change mitigation analysis [24]. A partial equilibrium model covering the Nordic forestry sector was hard-linked with an energy model covering the electricity and district heating sector in the Nordic countries to analyse the effects on the heat and power sector from large-scale forest-based biofuel production. The results indicated that studies not accounting for the competition for biomass may over-estimate future bioenergy production levels [23].

To reach the desired production level of biofuel production, it is necessary to identify the required investments, and in turn, the policy support levels required. These policy support levels have to make the investments profitable for the plant-owner but also need to consider the additional indirect cost, such as increased cost for other biomass using industries, which is of importance for policymakers.

This paper aims to identify the policy support levels required to facilitate large-scale investments in sawmill integrated production of LBG. The results will give an indication of the support needed to initiate investments in full-scale plants, considering current biomass market conditions. The paper also aims to estimate what levels of support that would be required when the biomass market has been affected by the large-scale implementation, which corresponds to the policy support necessary to maintain a large-scale biofuel production. Specifically, this work aims at answering the following questions:

- What are the policy support levels necessary to (1) facilitate the initial investments in large-scale biofuel production plants, and (2) maintain high production levels in the long-term under changed biomass market conditions?

- How is the economic performance of different biofuel production technologies affected by adopting either a plant-owner or a policymaker perspective?

To achieve this, we utilise a framework that combines technoeconomic modelling, supply chain cost optimisation and microeconomic partial equilibrium modelling through soft-linking. Sweden is used as the geographical scope, where the well-developed forest industry provides biomass competition and an ample selection of potential host sites. While the study encompasses the geographical boundaries of Sweden, the approach can be replicated for other geographical areas using similar models.

\section{Methodology}

We applied the interdisciplinary soft-linking framework presented by Zetterholm, Bryngemark, and Ahlström [25], which considers the biomass market impacts of introducing large-scale biofuel production.

\subsection{Techno-economic market evaluation framework}

The framework uses soft-linking of three sub-models that cover different aspects of the biofuel production system. The sub-models included are:

1) The plant-level model: identifies the plant-level performance from a plant-owner perspective. It results in the biomass-to-biofuel yield(s) and biofuel production cost as observed by the plant-owner.

2) The supply chain model: covers the specific location and plant data of host and competing industries and identifies the performance of the entire supply chain using the national borders as system boundaries, reflecting the system boundaries of a policymaker. It considers the location of biomass, host sites, and competing biomass users.

3) The market model: covers the market price formations and industry biomass demand. It simulates the market dynamics given a specified demand for domestically produced biofuels resulting in new biomass market equilibrium prices and forest industries production quantities.

Fig. 1 shows a schematic overview of how the different sub-models are linked and what data passes between the different models during the iterations.

Iterations of the biomass market prices, forest industry production, and biomass usage between the market and supply chain continue until the biomass prices, and forest industry production levels converge. The output of the framework is the economic performance of a biofuel production technology considering the biomass price impacts from the large-scale implementation of the technology in the system.

\subsubsection{Plant-level model}

The plant-level model determines the site-specific technology configuration and techno-economic performance of the plant from the perspective of the plant-owner. The plant-level technology configurations and the associated mass- and energy balances are based on previous work [2] where the configurations were determined using pinch-analysis $[26,27]$ to heat integrate the biofuel production facility with the host sawmills, applying different heat integration targets for the sizing of the facility.

The economic performance of the plant was determined using the annuity method to calculate the LBG production cost. Investment costs were taken from Ahlström et al. [2] and include the cost of purchased equipment, the direct costs, such as installation and buildings, and the indirect costs, such as start-up, contingency and working capital. 


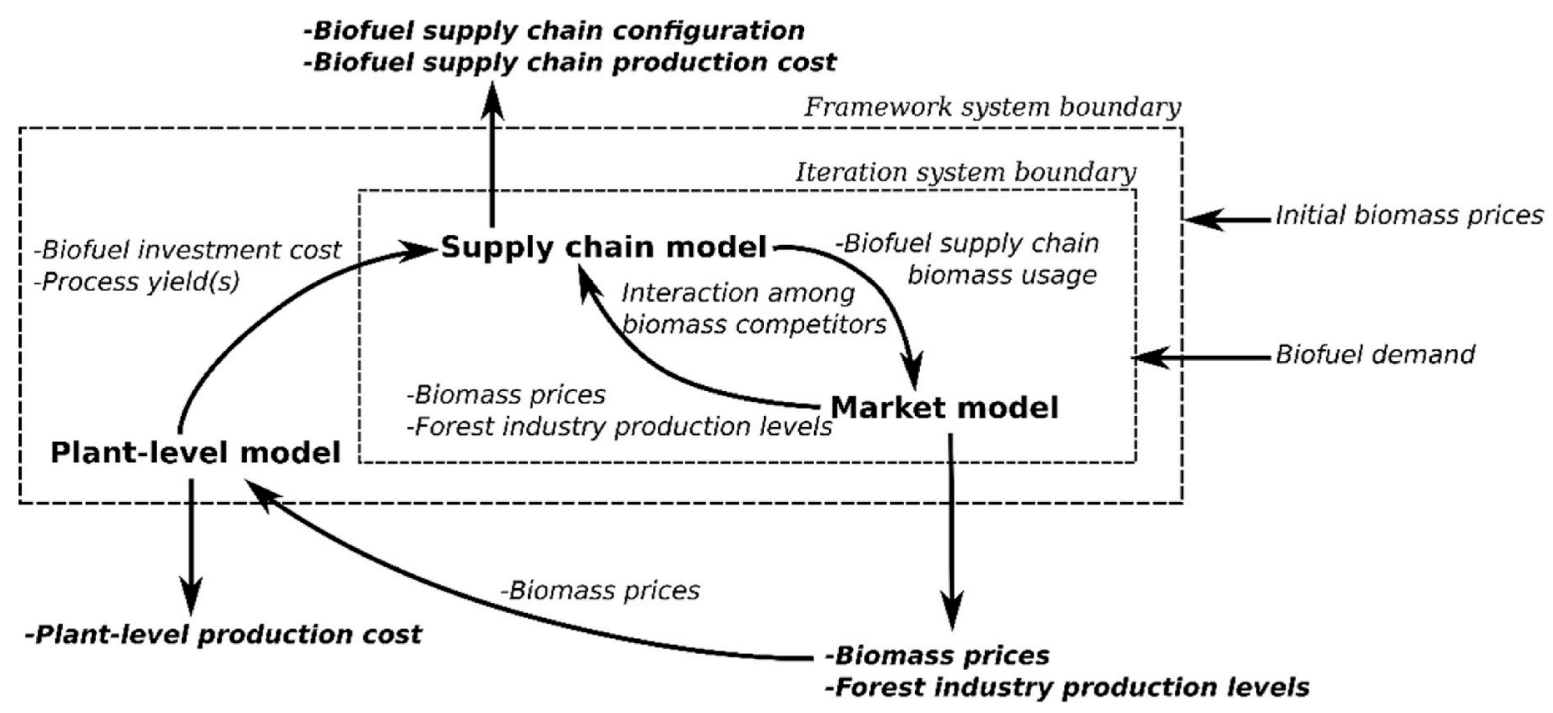

Fig. 1. Schematic overview of the iterative process in the modelling framework.

Operation and maintenance costs were estimated from the heat and mass balances accounting for external heating and cooling needs.

\subsubsection{Supply chain model}

The supply chain model used was the geographically explicit supply chain model BeWhere Sweden. BeWhere Sweden is a mixed-integer linear programming (MILP) model written in GAMS using CPLEX as a solver, see $[4,28]$ for a more detailed overview. The geographical scope of the model encompasses the national boundaries of Sweden and includes a large number of sites of importance for biomass supply and demand as well as site-specific data on energy and biomass use for competing industries and potential host industries. The model minimises the total system cost to satisfy a specified biofuel (LBG) demand considering the cost for energy carriers, transports, and investments. This is done by determining the location of production facilities and the flow of biomass in the entire system while simultaneously satisfying the biomass demand in other sectors (forest industry and stationary energy sector).

As commonly done in these types of models, the biomass prices are assumed to be static. Accordingly, the biomass prices and production quantities in other industries are not affected by the adaptation of a specific biofuel production technology (including the scale at which this is implemented). However, the biomass prices have spatial differences depending on, for example, local harvesting costs, transport costs, see [4].

The techno-economic performance of the site-specific technology configurations output by the plant-level model was used as input in the supply chain model. The supply chain model output includes the biofuel supply cost, the lowest cost locations of biofuel plants and the composition of the biomass assortments used for biofuel production. The biomass usage per assortment was used as input to the market model to represent the biofuel production technology.

\subsubsection{Market model}

The changes in the biomass market from the large-scale introduction of biofuel production were simulated using the partial equilibrium model, the Swedish forest sector trade model (SFSTM II) [13,29,30]. SFSTM II consists of two sub-models: a trade cost model that calibrates prices and feedstock allocation to a reference year, and model that can be used to simulate prices and feedstock allocations under various scenarios, such as the introduction of new biofuel production, taxes etc.

The market model simulates biomass feedstock prices and allocations in the forest biomass market in Sweden, including trade with the rest of the world. With the introduction of domestic biofuel production, the model generates new biomass feedstock prices and allocations within and between industries and sectors. The market consists of forest industries, bioenergy heat and power production, and biofuel production. Prices are simulated for raw materials (e.g. pulpwood), by-products (e.g. bark), intermediate products (e.g. pellets) and final products (e.g. plywood). Industries optimise production levels and feedstock use to maximise profits given feedstock prices, supply constraints, and the market demand for products (including by-products, intermediate products, and final products). The model is implemented in GAMS and uses the CONOPT solver to maximise consumer and producer surplus to obtain equilibrium prices and resource allocation [13]. The outputs in terms of new industrial production levels and biomass equilibrium prices after the implementation of biofuel production were used as inputs to the supply chain model.

\subsubsection{Performance indicators and modelling procedure}

This section describes the implementation of the modelling framework and the performance indicators used. Two different biomass market scenarios were considered describing if the biomass prices were determined internally in the modelling procedure (endogenous to the model) or if they were determined externally to the model and given as static values (exogenous to the model):

1) The current-exogenous (2016) biomass market scenario considers the biomass market without any endogenous changes from the deployment of new biofuel production.

2) The iterative-endogenous biomass market scenario incorporates the biomass market changes from the deployment of large-scale biofuel production. were:

The performance indicators used to evaluate the production of LBG

The direct production cost (DPC) is the cost of biofuel production from the plant-level model. It represents the biofuel selling price necessary for a profitable investment from a plant-owners perspective. DPC is calculated as in equation (1) according to [2]:

$D P C=\frac{\left(\sum\left(E_{i} \cdot\left(P_{i}+P_{t r, i} \cdot d_{t r, i}\right)\right)+I \cdot c r f+O \& M\right)}{E_{B F}}$

where $E_{i}$ is the annual plant input or output of commodity $i$ (e.g. electricity, biomass), $P_{i}$ is the respective prices, $P_{t r}$ is the transport cost, $d_{t r}$ is the transport distance, $I$ is the investment cost, $c f r$ is the capital recovery factor, $O \& M$ is the annual operation and maintenance cost, $E_{B F}$ 
represents the annual plant biofuel production.

The direct supply cost (DSC) is the direct supply cost of LBG from the supply chain model. DSC encompasses all direct costs associated with the LBG production. The direct supply cost is calculated as the average value for all LBG production facilities (see section 2.1.2) as shown in equation (2):

$D S C=\frac{\left(\sum_{j}\left(\sum_{i}\left(E_{i, j} \cdot\left(P_{i}+P_{f i x, t r, i}+P_{d e p, t r, i} \cdot d_{t r, i}\right)\right)+I_{j} \cdot c r f+O \& M_{j}\right)\right)}{E_{B F, t o t}}$ where index $j$ represents each facility, index $i$ represents each commodity, $P_{f i x, t r}$ is the fixed part of the transport cost (i.e. loading/ unloading of commodities), $P_{\text {dep,tr }}$ is the distance-dependent part of the transport cost, $d_{t r}$ is the transport distance of each commodity, $I_{j}$ is the investment cost of facility $j, c r f$ is the capital recovery factor, $O \& M_{j}$ is the operation and maintenance cost of facility $j$, and $E_{B F \text {,tot }}$ is the total annual domestic LBG production.

The total system supply cost (TSSC) shows the total LBG supply cost from the supply chain model which includes both the direct costs (e.g. costs directly associated with the biofuel production plants) and the

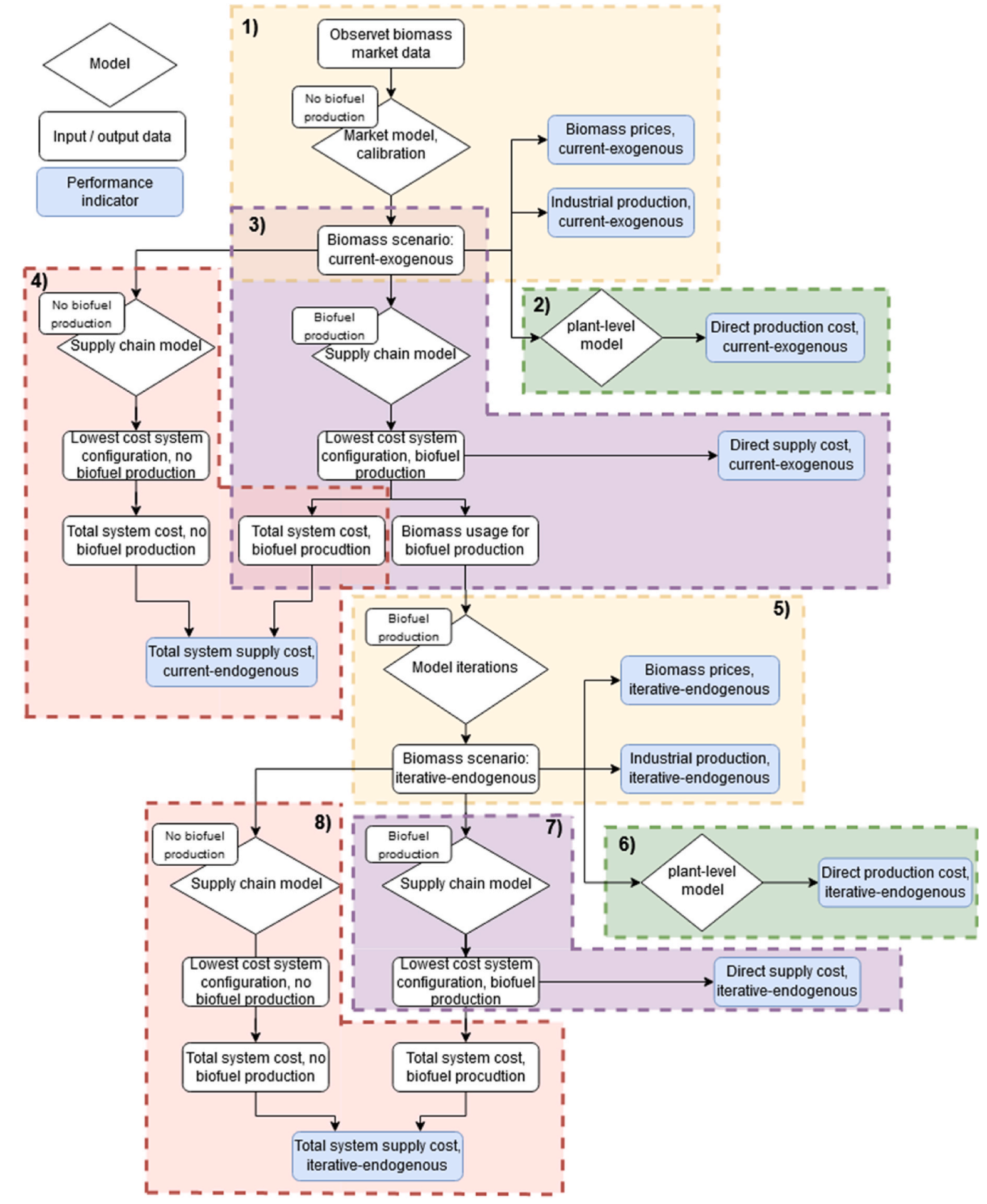

Fig. 2. Schematic overview of the calculation procedure. Boundaries for 5) encompasses the iteration system boundary in Fig. 1. 
indirect costs (e.g. increased costs for other biomass users). This can be analogous to the perspective of a policymaker which also needs to consider the indirect impact on other biomass using industries from the introduction of large-scale biofuel production. TSSC is estimated as in equation (3) and is a measure of the additional system cost of producing a specific amount of biofuel compared to no biofuel production:

$T S S C=\frac{\text { yyscost }_{B F}-\text { Syscost }_{n o B F}}{E_{B F, t o t}}$

where Syscost $_{B F}$ is the total system cost (see section 2.1.2) for the specific annual biofuel production and the biomass market scenario, Syscost $_{\text {noBF }}$ is the total system cost without any biofuel production in a given biomass market scenario (see Fig. 2), and $E_{B F \text {,tot }}$ is the total annual domestic LBG production.

Policy support cost (PSC) is a measure of the cost of financial support for a plant owner to have a profitable investment in a biofuel production plant. The direct policy support cost $\left(P S C_{\text {direct }}\right.$ ) is a measure of the policy support which would be necessary for the plant-owner to invest, and the indirect policy support cost $\left(\right.$ PSC $_{\text {indirect }}$ ) is the additional cost of the policy support that the policymaker observes in the form of increased costs for other biomass users.

$P S C_{\text {direct }}=D P C-P_{L N G}$

$P S C_{\text {indirect }}=T S S C-P_{L N G}-P S C_{\text {direct }}$

Comparing the policy support necessary under the current-exogenous and iterative-endogenous biomass market scenarios show both the policy support necessary to enable investments now, and that required for sustaining large-scale production after the biomass market characteristics have changed. The specific calculation procedure is shown in Fig. 2, followed by a detailed description.

1) Observed data for the biomass market (2016) (e.g. biomass prices, production levels, harvesting quantities) are used as input to the market model. The market model is calibrated using the trade cost minimisation part of the model resulting in the calibrated biomass prices and industrial production levels referred to as the currentexogenous biomass market scenario.

2) The calibrated biomass prices are used as input to the plant-level model, which calculates the direct production cost using the currentexogenous biomass market, using equation (1).

3) The current-exogenous biomass market data are used as input to the supply chain model together with the annual demand of domestically produced LBG. The supply chain model results in the lowest cost system configuration for the given biofuel demand. The system configuration is used to identify, the direct supply cost (calculated from equation (2)), the total system cost, and the biomass usage for producing LBG.

4) The current-exogenous biomass market data are used as input to the supply chain model which calculates the total system cost without any biofuel demand. The total system cost with and without domestic biofuel production is used to calculate the total system supply cost, see equation (3).

5) The biomass usage for biofuel production under the current-exogenous biomass market scenario is used as the initial representation of the biofuel production technology in the market model. The iteration procedure follows the iteration system boundaries in Fig. 1, and after convergence, the data for the iterative-endogenous biomass market scenario is obtained, and biomass prices and industrial production before (current-exogenous), and after (iterative-endogenous) the largescale implementation of biofuel production can be compared.

6) The plant-level model is used to calculate the direct production cost for the iterative-endogenous biomass market scenario, as in 2).

7) The supply chain model is used to calculate the direct supply cost for the iterative-endogenous biomass market scenario, as in 3).
8) The supply chain model is used to calculate the total system supply cost for the iterative-endogenous biomass market scenario, as in 4).

\subsection{System description and input data}

The technology used to determine the techno-economic performance of LBG production was based on previous work [2]. Three different site-specific sawmill-integrated configurations for the technology were evaluated and Sweden was used as the geographical scope where the forest industry provides both competing uses for the biomass, the supply of industrial by-products, and the potential host/integration sites.

The biomass assortments allowed as feedstocks to the biofuel production were limited to forest and forestry by-products, i.e. industrial by-products (sawdust and bark), wood chips, and tops and branches. This is in line with the EU waste hierarchy and the REDII directive [31], which favour waste and by-products for the production of second-generation biofuels production.

All calculations apply the monetary value year of 2016 using the exchange rate of 9.47 SEK/EUR [32]. The investment costs were converted to the 2016 monetary value year using the Chemical Engineering Plant Cost Index (CEPCI) [33].

\subsubsection{Technology configuration description and data}

The gasifier technology is based on a dual fluidised bed (DFB) gasification concept [34]. Specifically, this study utilised the process model presented in [35] for LBG production. The LBG plant was heat and feedstock integrated with a generic Nordic sawmill considering several different sizing criteria [2]. A steam cycle with a back-pressure turbine is used to generate electricity from the recovered excess heat. The steam mass flow from the turbine draw-offs was optimised for electricity generation utilising linear programming methods [36]. The LBG production plant size in relation to the host sawmill was determined according to the following criteria, each of which represents a distinct configuration in the study:

A) All available sawmill residues. The LBG plant was sized to use all of the on-site available residues (i.e. bark, sawdust, and wood chips) for biofuel production (and cover any additional heating demand at the sawmill). The plant-owner maximise the on-site LBG production capacity without needing to import additional feedstock.

B) Sawmill heat demand. The LBG plant was sized for all excess heat released from the biofuel production facility to cover the internal heat demand at the sawmill.

C) $500 \mathrm{MW}$ facility. The LBG plant was sized to produce $500 \mathrm{MW}_{\text {th }}$ of LBG, equalling a biomass input the size of a large Swedish pulp mill. The configuration represents a case where it would be deemed very profitable to produce LBG in large facilities.

The energy balances of the different configurations are shown in Table 1.

The annual electricity production for configuration C (in GWh) was determined according to equation (6):

Table 1

Energy balance (LHV) for each configuration normalised against the biomass input, derived from [2].

\begin{tabular}{llll}
\hline $\begin{array}{l}\text { Technology } \\
\text { configuration }\end{array}$ & $\begin{array}{l}\text { LBG produced } \\
{\left[\mathrm{MW}_{\text {Biofuel }} /\right.} \\
\left.\mathrm{MW}_{\text {Biomass }}\right]\end{array}$ & $\begin{array}{l}\text { Electricity used } \\
{\left[\mathrm{MW}_{\mathrm{el}} /\right.} \\
\left.\mathrm{MW}_{\text {Biomass }}\right]\end{array}$ & $\begin{array}{l}\text { Electricity } \\
\text { produced }\left[\mathrm{MW}_{\mathrm{el}} /\right. \\
\left.\mathrm{MW}_{\text {Biomass }}\right]\end{array}$ \\
\hline $\begin{array}{c}\text { A - All by- } \\
\text { products }\end{array}$ & 0.69 & 0.104 & 0.057 \\
$\begin{array}{c}\mathrm{B} \text { - heat } \\
\text { integration }\end{array}$ & 0.69 & 0.104 & 0.099 \\
$\mathrm{C}-500 \mathrm{MW}$ & 0.69 & 0.104 & $*$ \\
\hline
\end{tabular}

*Depending on the size of the sawmill, see equation (6) 
$E l=91.8 \cdot$ size $e^{-0.012}$

where the size is the annual production of the hosting sawmill in $\mathrm{m}^{3}$ of sawn wood. The annual operating time for the LBG facility was assumed to be $7838 \mathrm{~h} / \mathrm{a}$. Configuration $\mathrm{C}$ has a fixed biofuel plant size whereby the electricity output is dependent on the size of the sawmill.

The host sawmill used in the plant-level model was set to $250000 \mathrm{~m}^{3}$ annual production of sawn wood. In the supply chain model, all sawmills with a sawn wood production higher than $50000 \mathrm{~m}^{3}$ of were included as possible host locations.

Both the plant-level and supply chain evaluations used a capital recovery factor of 0.1 , corresponding to a discount rate of $8 \%$ and an economic lifetime of 20 years. Presented in Table 2 are the investment cost correlations for the different configurations depending on the size of the hosting sawmill.

\subsubsection{Forest industries}

Swedish forest industries not only provide an ample selection of competing uses for the forest biomass but also opportunities for host sites (sawmills) with on-site availability of sawmill by-products.

The data used to represent different industries rely partly on different datasets due to the required resolution in the models. The host sawmill in the plant-level model was represented in terms of heat demand and availability of by-products, based on a generic Nordic sawmill [37].

The site-specific production levels for each sawmill and mechanical pulp mill in BeWhere Sweden were determined from the Swedish Forest Industries Federation (SFIF) data [38]. Missing sawmills data was complemented with additional data gathering from their respective websites. The internal heat demand and by-product (sawdust, wood chips, and bark) availability at each sawmill were calculated using general correlations [39]. The chemical pulp mills were modelled mainly with data from Wiberg and Forslund [40], and supplemented with data from SFIF [38]. For more details and site-specific assumptions, see $[4,28]$.

\subsubsection{Forest biomass supply and demand}

The competing forest industries considered were sawmills (both competing industries and potential host sites), stationary energy sector, pulp- and paper mills, and pellets production. Table 3 shows the biomass assortments allocated to each category.

Table 4 shows the maximum biomass harvest potentials for each biomass assortment, which are the same amount in BeWhere Sweden and SFSTM II. The "today's forestry" scenario from the Swedish Forest Agency impact assessment (SKA 15) [41] was used to describe the theoretical potentials for future harvest (final felling and thinning) assuming current practices. The spatial distribution of the biomass was estimated using a bottom-up approach described in detail in [4,42,43]. Both BeWhere Sweden and SFSTM II considers the availability of industrial by-products as functions of the production levels of the forestry industries. However, there are differences in the treatment of harvesting residues, which are defined exogenously in BeWhere, while in SFSTM II they are estimated from the model results from the harvest of virgin wood.

Table 2

Investment cost correlation for each configuration depending on the size of the host sawmill, derived from [2]. $\mathrm{X}$ is the annual production of sawn wood in $\mathrm{m}^{3}$.

\begin{tabular}{llll}
\hline InvestmentCost $=c_{1} \cdot X^{c_{2}}\left[\right.$ MEUR $\left._{2016}\right]$ & & & \\
\hline Technology configuration & $c_{1}$ & $c_{2}$ & $\mathrm{R}^{2}$ \\
A-All by-products & 0.0140 & 0.73 & 0.999 \\
B-heat integration & 0.0362 & 0.69 & 0.999 \\
C-500 MW & 704 & 0.0077 & 0.999 \\
\hline
\end{tabular}

\subsection{Model calibration and linking}

\subsubsection{Model calibration}

The biofuel production, the biomass prices, and the forestry products are outputs from SFSTM II and were calibrated against the 2016 data on the biomass market for biomass prices, current harvesting levels, and industrial production levels using the trade cost minimisation part of the model. For more details on calibration see [13]. The current harvesting levels were from SFA and FAO Statistics [44-46].

The base year biomass prices used in the calibration are shown in Table 5 together with the prices for purchased and sold electricity. The production levels for the forest industries used as inputs to the market model for the model calibration are shown in Table 6 .

b Industrial by-products are represented aggregate in BeWhere Sweden, while sawdust and bark are individually represented in SFSTM II, the price of industrial by-products in BeWhere Sweden is averaged against the traded volumes of sawdust and bark.

${ }^{c}$ Roundwood prices in EUR $/ \mathrm{m}^{3}$ fub, before price calibration. Price data on the wood type (sawlog or pulpwood) and tree species are from [44]. The basic disaggregation into regions is based on the regionally disaggregated data in [44] and then manually adjusted (with approximation) to the regions of SFSTMII presented by [30]. The conversion factor used for coniferous wood $0.458 \mathrm{~m}^{3} \mathrm{fub} / \mathrm{MWh}$, and non-coniferous $0.386 \mathrm{~m}^{3} \mathrm{fub} / \mathrm{MWh}$ [52].

d There is no official price data for harvest residues (tops and branches); instead, the price is based on estimations from [30], see [30, 53] for more information regarding the estimations. The conversion factor used for tops and branches was $0.208 \mathrm{~m} 3 \mathrm{fub} / \mathrm{MWh}$ [52].

\subsubsection{Model linking}

BeWhere Sweden and SFSTM II differ in their representation of biomass assortments, the spatial resolution. Table 7 shows the different biomass assortments represented in the two models.

The differences in the biomass assortments create difficulties in that the market model has both coniferous and non-coniferous biomass assortments, not represented in the supply chain model. Likewise, there is a difference in that the supply chain model differentiates between biomass from final felling and biomass from thinning. These differences were resolved by adjusting the prices in BeWhere Sweden so there is no differentiation between final felling and thinning. In the case where several biomass assortments in the SFSTM II were used to calculate new biomass prices in BeWhere Sweden, the prices were weight-adjusted for the total production volumes.

Since industrial production is represented at the regional level in SFSTM II and for each specific site in BeWhere Sweden, the underlying data for the base year can result in discrepancies in the total national production between the two models. The total production for each industry branch in BeWhere Sweden was calibrated to the production levels in SFSTM II by applying a general factor adjusting the production volume of each site.

The geographical representation in BeWhere Sweden has 334 grid cells with a half-degree spatial resolution, whereas the SFSTM II is divided into four regions. The differences in the geographical representation were addressed in the iteration procedure by using the same biomass prices in each grid cell belonging to the region representated in SFSTM II. The industrial production levels passed from the SFSTM II to BeWhere Sweden were however treated on a national scale. This was done since SFSTM II treats the production in the regions similarly while BeWhere Sweden has individual representation. If a specific region would be host to both an efficient and inefficient industrial site, both would be affected by any increase, or decrease in production - while it would be more likely that inefficient sites would be the first to decrease production, rather than efficient. Since the SFSTM II does not identify which particular sites reduces their production the production was decided to be treated on a national scale. 
Table 3

Biomass assortments allocated to each forest industry category (in the BeWhere Sweden model).

\begin{tabular}{|c|c|c|c|c|c|c|c|}
\hline \multirow[b]{2}{*}{ Demand sector } & \multicolumn{7}{|c|}{ Biomass assortments } \\
\hline & Sawlogs & Pulpwood & Tops and branches & Wood chips & Industrial by-products & Waste wood & Pellets \\
\hline Sawmills (sawn products) & $\mathrm{x}$ & & & & & & \\
\hline Sawmills (heat demand) & & & $\mathrm{x}$ & $\mathrm{x}$ & $\mathrm{x}$ & & \\
\hline Pulp and paper mills (pulp) & $\mathrm{x}$ & $\mathrm{x}$ & & $\mathrm{x}$ & & & \\
\hline Pulp and paper mills (heat demand) & & $\mathrm{x}$ & $\mathrm{x}$ & $\mathrm{x}$ & $\mathrm{x}$ & $\mathrm{x}$ & \\
\hline Pellets production plants & & & & $\mathrm{x}$ & $\mathrm{x}$ & & \\
\hline Stationary energy $\left(\mathrm{DH}^{\mathrm{a}}\right.$ and $\left.\mathrm{CHP}^{\mathrm{b}}\right)$ & & $\mathrm{x}$ & $\mathrm{x}$ & $\mathrm{x}$ & $\mathrm{x}$ & $\mathrm{x}$ & $\mathrm{x}$ \\
\hline LBG production & & & $\mathrm{x}$ & $\mathrm{x}$ & $\mathrm{x}$ & & \\
\hline
\end{tabular}

${ }^{\mathrm{b}}$ Combined Heat and Power plant.

a District Heating.

Table 4

Maximum biomass harvesting potentials.

\begin{tabular}{ll}
\hline & Supply potential [TWh/a] \\
\hline Sawlogs & 89 \\
Pulpwood & 69 \\
Tops and branches & 31 \\
\hline
\end{tabular}

Table 5

Base scenario market prices.

\begin{tabular}{|c|c|c|c|}
\hline & Commodity & $\begin{array}{l}\text { Base year prices [EUR/ } \\
\mathrm{MWh}_{\mathrm{LHV}} \text { ] }\end{array}$ & Source \\
\hline Electricity sold & & 29.1 & [47] \\
\hline Electricity purchased & & 41.7 & [48] \\
\hline \multirow[t]{3}{*}{ Sawlogs } & Pine & 22.0 & {$[44]^{c}$} \\
\hline & Spruce & 25.0 & {$[44]^{c}$} \\
\hline & $\begin{array}{l}\text { Non- } \\
\text { Coniferous }\end{array}$ & 21.6 & {$[44]^{\mathrm{c}}$} \\
\hline \multirow[t]{3}{*}{ Pulpwood } & Pine & 12.8 & {$[44]^{\mathrm{c}}$} \\
\hline & Spruce & 12.2 & {$[44]^{c}$} \\
\hline & $\begin{array}{l}\text { Non- } \\
\text { Coniferous }\end{array}$ & 13.5 & {$[44]^{\mathrm{c}}$} \\
\hline \multirow{2}{*}{$\begin{array}{l}\text { Industrial by- } \\
\text { products }^{\text {b }}\end{array}$} & Sawdust & 24.5 & [49] \\
\hline & Bark $^{\mathrm{a}}$ & 11.0 & [49] \\
\hline Tops and branches & & 17.1 & {$[30]^{\mathrm{d}}$} \\
\hline Wood chips & & 18.7 & [49] \\
\hline Pellets & & 25.7 & $\begin{array}{l}{[50,} \\
51]\end{array}$ \\
\hline
\end{tabular}

a Assumed price $20 \%$ lower than sawdust on a volumetric basis.

Table 6

Forest industry production levels in 2016, aggregated on the product category.

\begin{tabular}{llll}
\hline Industry & Product & $\begin{array}{l}\text { Base year } \\
\text { production }\end{array}$ & Source \\
\hline Pulp and paper industry & Chemical pulp & $\begin{array}{l}7.81 \text { million } \\
\text { tonnes }\end{array}$ & {$[54]$} \\
& Mechanical pulp & $\begin{array}{l}3.85 \text { million } \\
\text { tonnes }\end{array}$ & {$[54]$} \\
& Sawn pine & 6.7 million $\mathrm{m}^{3}$ & {$[54]$} \\
Sawmill & Sawn spruce & 10.4 million $\mathrm{m}^{3}$ & {$[54]$} \\
& Sawn non- & 0.12 million $\mathrm{m}^{3}$ & {$[54]$} \\
& coniferous & 1.8 million tonnes & {$[54]$} \\
Pellets & Wood pellets & 17 TWh & {$[55]$} \\
Stationary energy $\left(\mathrm{DH}^{\mathrm{a}}\right.$ and & District heating & & \\
$\mathrm{CHP}^{\mathrm{b}}$ ) & & & \\
\hline
\end{tabular}

${ }^{\mathrm{b}}$ Combined Heat and Power plant.

a District Heating.

\subsection{Biofuel demand scenarios}

Two biofuel demand scenarios in which the total production of LBG equals 4 and $8 \mathrm{TWh} / \mathrm{a}$, respectively, were modelled. The two scenarios were treated as fixed demand scenarios in which the biofuel demand was met by domestic production. The LBG produced is assumed to be used in
Table 7

Differences and connection between different biomass representations.

\begin{tabular}{lll}
\hline $\begin{array}{l}\text { Major biomass assortment } \\
\text { categories }\end{array}$ & $\begin{array}{l}\text { BeWhere Sweden biomass } \\
\text { assortments }\end{array}$ & $\begin{array}{l}\text { SFSTM II biomass } \\
\text { assortments }\end{array}$ \\
\hline Pulpwood & Final felling, thinning & $\begin{array}{l}\text { Pine, spruce, non- } \\
\text { coniferous } \\
\text { Pine, spruce, non- } \\
\text { coniferous }\end{array}$ \\
Sawlogs & Final felling, thinning & $\begin{array}{l}\text { Harvesting residues } \\
\text { Bark, sawdust }\end{array}$ \\
$\begin{array}{l}\text { Tops and branches } \\
\text { Industrial by-products } \\
\text { Pellets }\end{array}$ & $\begin{array}{l}\text { Final felling, thinning } \\
\text { Industrial by-products }\end{array}$ & $\begin{array}{l}\text { Pellets } \\
\text { Wood chips }\end{array}$ \\
\hline
\end{tabular}

the transport sector, potential future use in other sectors, such as iron and steel is not considered. These demand levels can be compared with a future scenario for high gaseous fuel usage in the Swedish transport sector with a demand of $4.3 \mathrm{TWh} / \mathrm{a}$ gaseous fuels in 2040 [56]. Additionally, it can be compared with the current (2019) usage of $3.9 \mathrm{TWh} / \mathrm{a}$ fossil fuels used for heating purposes in the Swedish iron and steel industry, which could be a sector needing LBG to remove fossil emissions [57].

\section{Results and discussion}

The market model was calibrated against the base year data (see section 2.3.1), resulting in the current-exogenous biomass market scenario. Appendix A shows the comparison between the base year data and the current-exogenous biomass scenario data.

\subsection{Production and supply costs}

Fig. 3 shows the calculated direct production cost, direct supply cost, and total system supply cost for the different technology configurations, biomass market scenarios (current-exogenous, iterative-endogenous), and biofuel (LBG) demand scenarios (4 and 8 TWh/a).

Unsurprisingly, all performance indicators increased as a result of changing from the current-exogenous to iterative-endogenous biomass market scenario. The cost increases were particularly notable for the 8 TWh/a biofuel demand scenario, which registered an increase of 8-17 EUR/MWh (14-25\%) for the direct production cost, 17-21 EUR/MWh (28-38\%) for the direct supply cost, and 11-13 EUR/MWh (13-19\%) for the total system supply cost upon changing from the current-exogenous to the iterative-endogenous biomass market scenario.

The total system supply cost experienced a smaller increase compared with the direct production cost and the direct supply cost when changing from the current-exogenous to the iterative-endogenous biomass market scenario. This is a consequence of the total system supply cost incorporating the impact on other biomass users. The change from the currentexogenous to the iterative-endogenous biomass market scenario resulted in a decreased biomass demand in the pellets industry due to decreased pellets production (see section 3.2). As the value of the forest industry products in BeWhere Sweden were not included in the total system cost, 

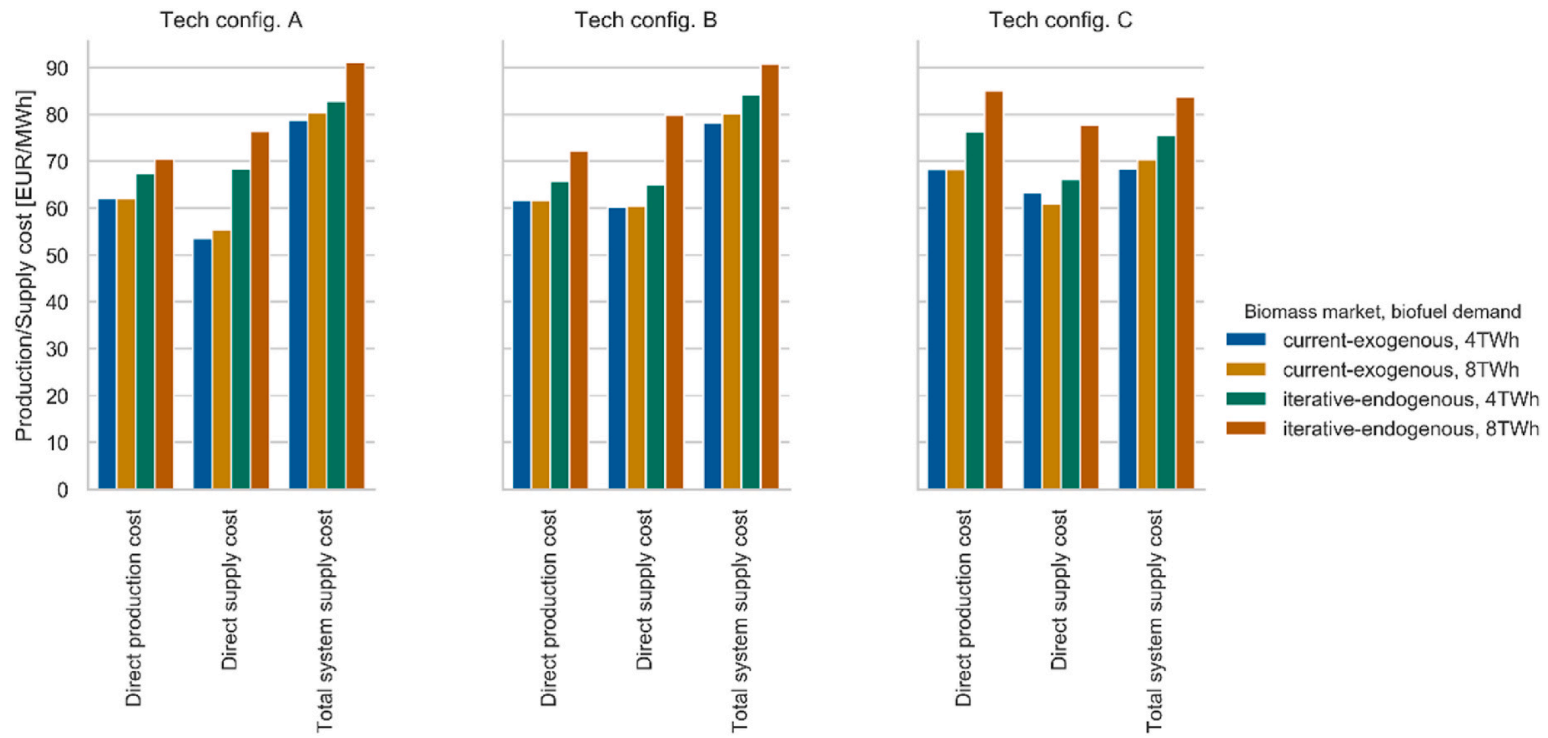

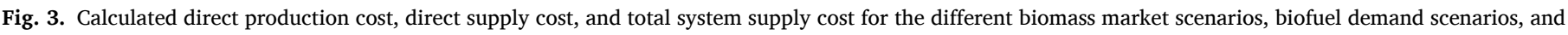
technology configurations.

the reduced biomass demand from the pellets industry lowers the total system cost. This led to a lower increase in the total system supply cost from the increased biomass price by changing the biomass market scenario, compared to the direct production cost, and the direct supply cost.

For the direct production cost and direct supply cost technology configuration A (LBG plant sized to utilise all available on-site byproducts) was the technology configuration most heavily affected by changes to the biomass market in both biofuel demand scenarios. Being able to fully satisfy biomass demand with onsite biomass by-products makes the use of imported by-products, such as tops and branches, with their associated transport costs more expensive. However, technology configuration A had the lowest increase in the total system supply cost, albeit being that there were small differences between the technology configurations for this performance indicator.

The direct production cost measures the biofuel production cost for the plant-owner. If the direct production cost shows that a biofuel production technology is profitable from a plant-owners perspective, several investors will likely deploy that technology. It is therefore of importance for the plant-owner to consider the increase in direct production cost in a dynamic biomass market when evaluating technology viability. Additionally, the performance of a specific technology configuration can be influenced by the inclusion of the biomass market impacts from the introduction of large-scale biofuel production. This is reflected in Fig. 3, where technology configuration A has the lowest direct production cost in the current-exogenous biomass market scenario, whereas technology configuration B (LBG facility dimensioned for the excess heat to cover the heat demand of the sawmill) is favoured under the iterative-endogenous biomass market scenario. That technology configuration B is favoured under the iterative-endogenous biomass market scenario is a result of the cost of biomass accounting of a smaller share of the direct production cost.

The total system supply cost, which measures biofuel production cost from a policymaker perspective, was consistently lowest for technology configuration C (sized for 500 MW of LBG production), in all biomass market and biofuel demand scenarios. This is in contrast with the direct production cost that was, in general, higher for technology configuration $\mathrm{C}$, showing that while the total system supply cost is lower for technology configuration $\mathrm{C}$, a larger share of that cost is carried by the plant-owner.

As the fuel output for technology configuration $\mathrm{C}$ is significantly larger than the other configurations, fewer facilities are needed to meet the biofuel demand scenarios. This results in geographically restricted areas with increased biomass demand, thereby reducing the number of other industrial sites affected by an increased biomass transport cost.

\subsection{Biomass market impacts}

Fig. 4 shows the change in the biomass prices after the large-scale implementation of biofuel production (iterative-endogenous) for the different scenarios, compared to the current-exogenous biomass prices.

For all scenarios, there is a high impact on the prices for wood chips (42-149\%), tops and branches (42-87\%), and industrial by-products (115-646\%), explained by the demand from LBG production. The high price increase for industrial by-products is explained by its low starting price, see Appendix A. In addition to this, the pellets prices increased (15-40\%) due to the price increase of its main feedstock (industrial by-products). The resulting pellets price increase resulted in decreased pellets production up to $50 \%$, see Fig. 5 which shows the changes in industrial production. The pulpwood and sawlogs prices remained largely unaffected since these feedstocks were not allowed for the production of LBG.

Technology configuration A resulted in higher biomass price increases compared to the other technology configurations, also reflected in that this configuration had the highest increases in the direct production and supply costs. This was especially true for the $4 \mathrm{TWh} / \mathrm{a}$ biofuel demand scenario where the industrial by-products price increase was significantly higher compared to the other technology configurations, which is reflected in Fig. 5 where the pellets production decrease is significantly higher compared to technology configuration B. However technology configuration $\mathrm{C}$ combines a relatively low price increase for the industrial by-products, with the highest pellets production decrease for the $4 \mathrm{TWh} / \mathrm{a}$ biofuel demand scenario. In this particular scenario, the substantial decrease in the pellets production counteracted the increase in demand for industrial by-products from the LBG production.

The results show that the increased competition for the forest and forestry by-products resulted in a significant decrease in the pellets production, ranging from $10 \%$ to $50 \%$, while the other industrial branches remained unaffected. This indicates that policy intervention that mandates biofuel production from biomass assortments complying with the RED II directive results in a reallocation of biomass resources from pellets to biofuel production. The benefits from the introduction of the biofuel production thus need to consider the alternative fuels that will replace the use cases currently fulfilled by pellets.

BeWhere Sweden does not consider the prices for the products from 


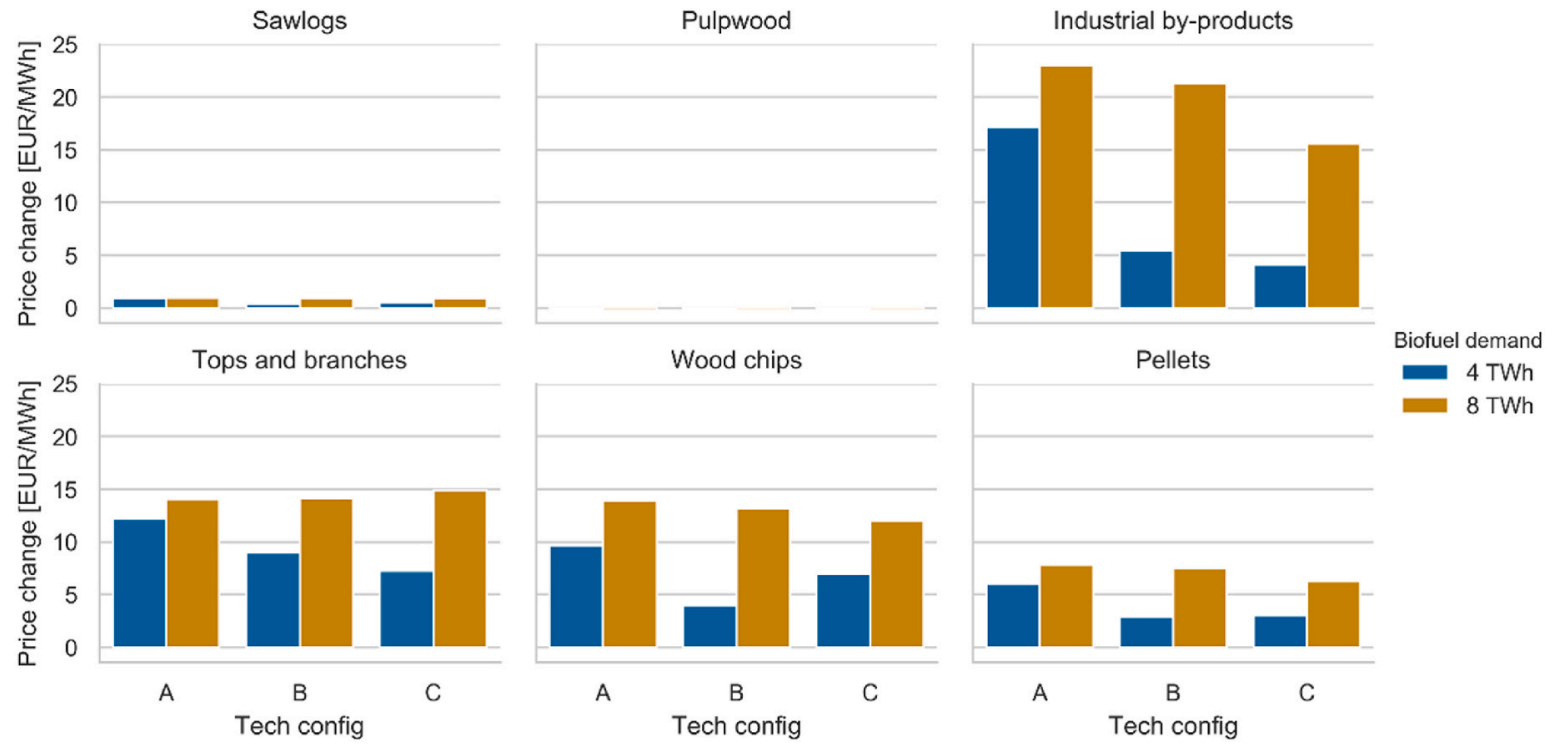

Fig. 4. Biomass price changes from the current-exogenous biomass market scenario.
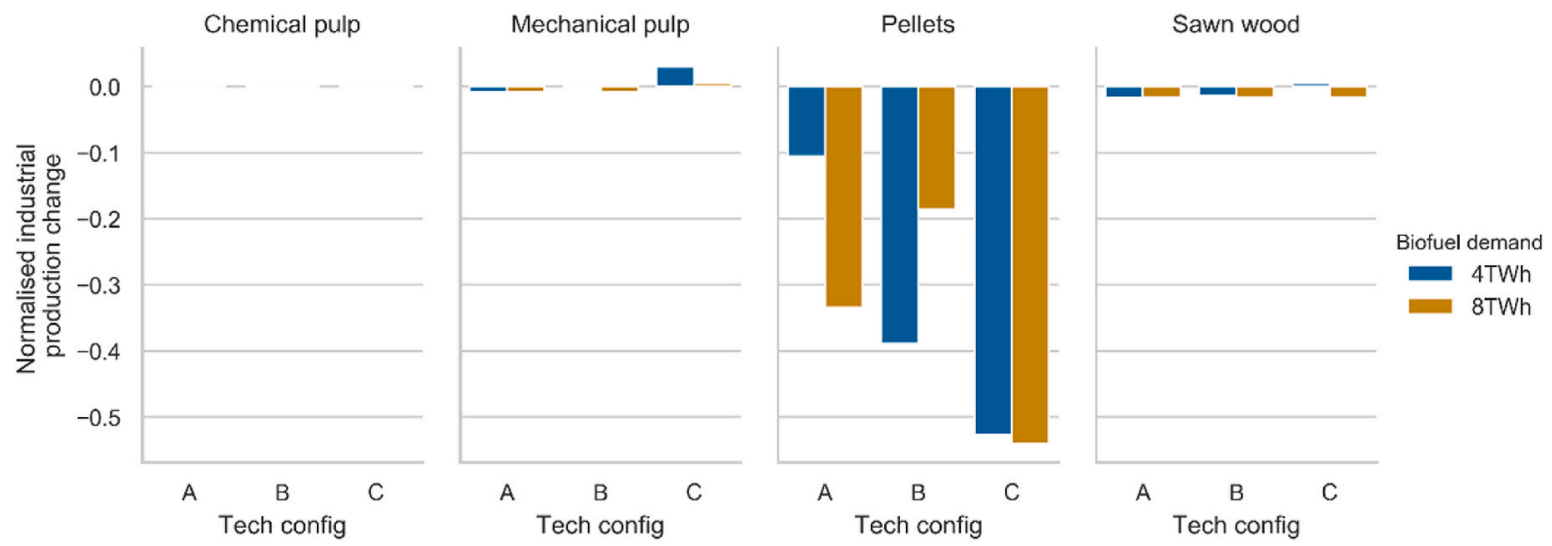

Fig. 5. Biofuel production impact on the production of the forest industries shown from the use of the iterative framework.
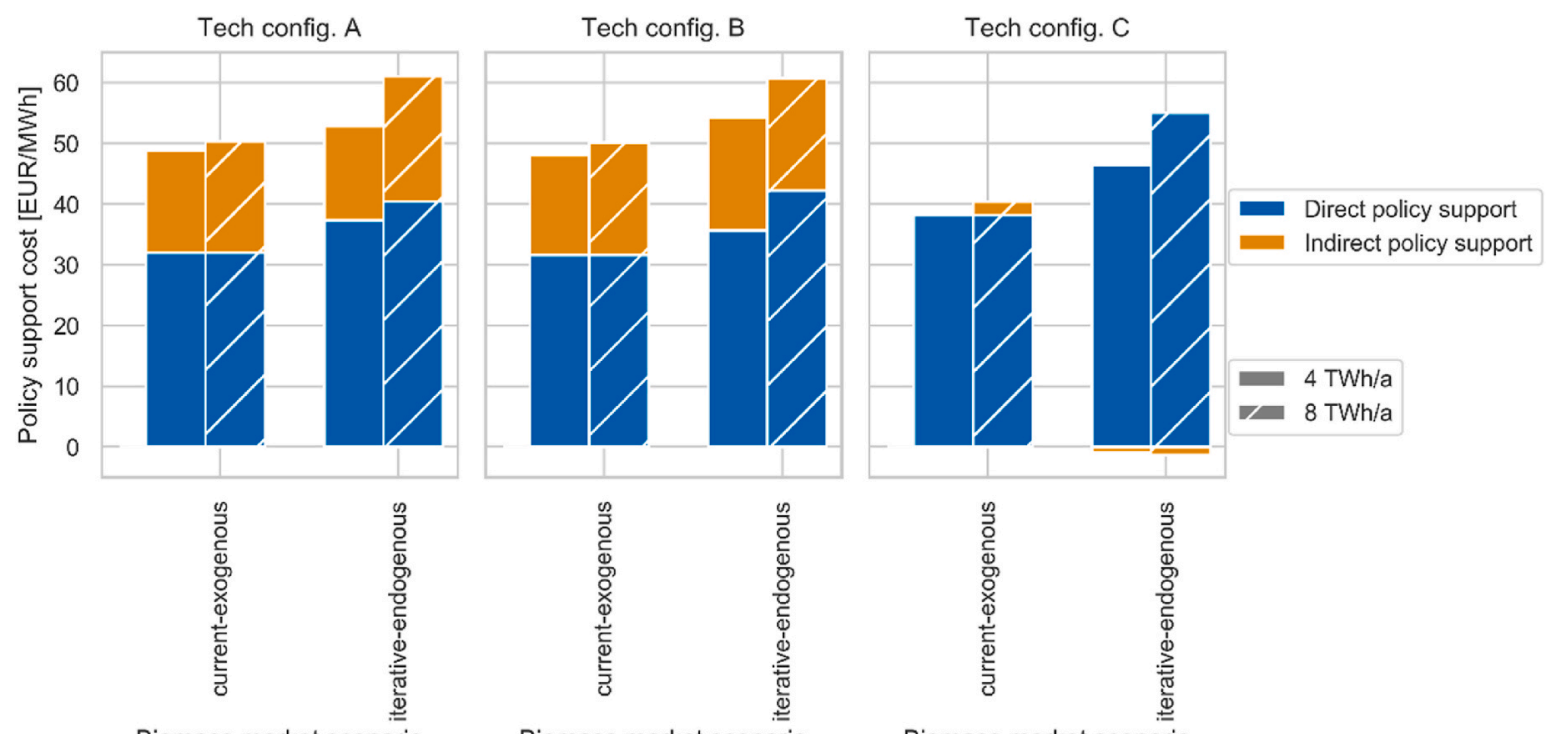

Biomass market scenario

Biomass market scenario

Fig. 6. Direct and indirect policy support cost. 
the traditional forest industries, i.e. pulp, paper, and sawn wood. Given that there are small changes in the production of these goods, there should be low impact on the system cost from these changes. However, there could be scenarios resulting in negative impacts on the production levels of the traditional forest industries, which should be considered when evaluating the total system cost of the introduction for biofuel production, especially since they are major exporting industries in Sweden.

\subsection{Required policy support}

The direct and indirect policy support costs for a current EU LNG market price of 30 EUR/MWh [58] are shown in Fig. 6. The market price is without any sector-specific taxes, therefore the direct policy support cost can be interpreted as to also include eventual sector-specific taxes affecting the fossil fuel alternative but not affecting the LBG.

A plant-owner required a direct policy support of 32-38 EUR/MWh for an investment to be profitable in the current-exogenous biomass market scenario. The support increased to 36-56 EUR/MWh (13-44\%) in the iterative-endogenous biomass market scenario. This shows that without including a dynamic biomass market model in the calculation, the direct policy support required to sustain large-scale biofuel production in the future is underestimated.

Using the perspective of a policymaker, the total policy support cost (including both the direct and indirect policy support cost) increased from 38 to 50 EUR/MWh in the current-exogenous biomass market scenario to 45-61 EUR/MWh in the iterative-endogenous scenario. Among the biofuel demand scenarios, the increase in total policy support cost was substantially greater for the $8 \mathrm{TWh} / \mathrm{a}$ scenario than for the $4 \mathrm{TWh} / \mathrm{a}$ alternative.

Technology configurations A and B resulted in a lower direct policy support cost compared to technology configuration C, which would make these configurations appear more favourable from the perspective of a policymaker focused on direct costs only. However, ignoring indirect policy support cost when analysing technology configurations can lead to policies that misestimate the full magnitude of the required support.

Technology configuration $C$ resulted in the lowest total policy support cost where the indirect policy support cost also became negative. This is explained by the direct policy support cost being calculated for a specific sawmill size (250 $000 \mathrm{~m}^{3}$ annual production of sawn wood). Meanwhile, the indirect policy support cost was based on the total system supply cost, which is an average system cost that also includes larger sawmills. Given the large LBG production capacity of technology configuration $\mathrm{C}$, the benefits of heat integration with the host sawmill are small. However, benefits can be improved by integration with larger sawmills, see [2]. In summary, the results in Fig. 6 show that the policy support should be developed to consider the total policy support cost, and should encourage the plant-owners to invest in technologies with the lowest total system supply cost, rather than the lowest direct production cost.

\subsection{Implications from using the framework}

Compared to traditional techno-economic approaches for evaluating different biofuel production technologies (e.g. plant-level, and supply chain evaluations), the use of an iterative framework show partly different results regarding technology performance, both from a plantowner and a policymaker perspective. These differences concern both how the biomass price impacts the production costs, but also how the different technologies integrated into the system affect industries competing for the biomass resources.
Comparatively examining the economic performance under the current-exogenous and iterative-endogenous biomass market scenarios highlight how biomass price changes affect the economic performance of the biofuel production technologies. Such a comparison can help reduce the uncertainty surrounding the long-term economic performance of a technology for a plant-owner. For policymakers, it can indicate the policy support levels necessary for constructing the first profitable plant, and to sustain large-scale production. In this work, the policy support levels were calculated as direct support per unit of produced biofuel. However, when developing policy support mechanisms, the policymaker also needs to consider how other industries are affected by the introduction of that policy support. The studied system in this work resulted in decreased production of pellets as the primary feedstock (sawdust) was instead used for LBG production. Pellets are mainly used for combustion purposes where it would be comparatively easy to change to other biomass feedstocks, compared with use-cases for LBG, which currently use LNG.

The results highlight the differences in the cost for the technology configurations when applying a plant-owner or a policymaker perspective and show that a technology configuration favoured by one is not necessarily favoured by the other. It is therefore important to consider the indirect costs of technologies when developing policy support to favour technologies with a low total system cost.

\section{Conclusions}

The introduction of large-scale biofuel production will impact both biomass prices and production at other biomass-consuming industries. Our results show that profitable investments in the production of liquefied biomethane (LBG) integrated with sawmills would require a policy support level in the range of 32-38 EUR/MWh under current (2016) biomass market conditions. When also explicitly considering the biomass market impacts from the introduction of large-scale forestbased biofuel production, the necessary policy support increases by $13-44 \%$. This shows that excluding these market impacts would result in substantial underestimation of the policy support level necessary to maintain a large-scale biofuel production, while it still can be sufficient to enable the first investments. Traditional scenario- or sensitivity-based analysis can identify the impact of market price changes on the economic performance of a technology but it neglects the endogenous price impact from large-scale deployment of that specific technology.

The use of a framework such as the one applied in this work explicates the additional system cost from the large-scale implementation of a biofuel production technology. It can thus be used to identify not only the additional support needed to enable a profitable first-of-a-kind production facility, but also the support necessary to maintain sizeable biofuel production. The solutions with the lowest direct cost for the plant-owner are not necessarily the same as those preferred by a policymaker owing to the occurrence of indirect costs. These indirect costs need to be considered when developing policy support in order to promote technologies with a low total system cost.

\section{Acknowledgements}

The work has been carried out under the auspices of Forskarskola Energisystem financed by the Swedish Energy Agency. Economic support from Bio4Energy, a strategic research environment appointed by the Swedish government, is also gratefully acknowledged. We thank Patrik Söderholm, Elisabeth Wetterlund and Simon Harvey who provided insight and expertise that greatly assisted the research. 


\section{Appendix A. Market model calibration}

SFSTM II was calibrated using market data from 2016 (forest industry production levels, biomass prices, and harvesting volumes). The 2016 input was used as a reference to the model when generating the current state of the biomass market via the model's demand and supply functions. If a model is a perfect mirror of the real market and there no market inefficiencies exist in the real market, the calibrated model will generate market prices and flows of biomass products equal to observed data. However, since a model is a simplification of reality, data shortages exist and the actual market complexity goes beyond perfect competition, deviations between observed market prices and simulated markets prices are expected. Nevertheless, it is of interest to understand these deviations to understand possible impacts on the simulated market scenarios.

Table A1 and Table A2 summarise observed biomass price data from 2016 used for calibrating SFSTM II, and the calibrated biomass price data from the SFSTM II constituting the current-exogenous biomass market scenario.

Table A1

2016 biomass prices used for calibrating the SFSTM II model and the calibrated biomass prices from SFSTM II constituting the current-exogenous biomass market scenario.

\begin{tabular}{|c|c|c|c|}
\hline & & Biomass prices $\left[\mathrm{EUR} / \mathrm{MWh} \mathrm{h}_{\mathrm{L}}\right.$ & \\
\hline \multirow{4}{*}{ Sawlogs } & & Observed data (year 2016) & Calibrated data (Current-exogenous) \\
\hline & Average sawlogs & & 21.3 \\
\hline & Pine & 22.0 & 18.1 \\
\hline & Spruce & 25.0 & 23.3 \\
\hline \multirow{3}{*}{ Pulpwood } & Non-Coniferous & 21.6 & 14.4 \\
\hline & Average pulpwood & & 10.7 \\
\hline & Pine & 12.8 & 10.8 \\
\hline \multirow{5}{*}{ Industrial by-products } & Spruce & 12.2 & 10.5 \\
\hline & Non-Coniferous & 13.5 & 11.2 \\
\hline & Average industrial by-products & & 3.6 \\
\hline & Dust & 24.5 & 3.6 \\
\hline & Bark & 11.0 & 3.3 \\
\hline Tops and branches & & 17.1 & 17.1 \\
\hline Wood chips & & 18.7 & 9.4 \\
\hline Pellets & & 25.7 & 19.4 \\
\hline
\end{tabular}

Table A2

Forest industry production levels for 2016, and the current-exogenous biomass market scenario, aggregated on the product category.

\begin{tabular}{llll}
\hline & Observed data (year 2016) & Calibrated data (Current-exogenous) & Unit \\
\hline Chemical pulp & 7.81 & 8.2 & million tonnes/a \\
Mechanical pulp & 3.85 & 3.6 & million tonnes/a \\
Sawn wood* & 17.22 & 18.0 & million $\mathrm{m}^{3} / \mathrm{a}$ \\
Pellets & 1.8 & 1.1 & million tonnes/a \\
\hline
\end{tabular}

Overall, the simulated market prices and biomass supply were approximately the same as the observed data. Some deviations were however notable: the price of non-coniferous sawlogs and the prices of forest industry by-products (sawdust, bark and wood chips). The difference suggests that the model is not representing all the segments in the market that form forest biomass product prices, i.e., some demands and/or supplies of biomass products are not represented in the model. Though this is an expected outcome given the partial equilibrium model approach (model boundaries are imposed) and non-perfect data, these differences need to be well understood to ensure model reliability.

Sawn wood is typically produced from spruce and pine, but occasionally also from non-coniferous species (less than $1 \%$ of all sawn wood production in Sweden). The calibrated price was roughly $70 \%$ of the actual market price. Since the supply, demand and trade of non-coniferous sawlogs are small and they can be substituted with other sawlog species, the model price formation of non-coniferous sawlogs is sensitive to small changes in the observed data. Since this tree species constitute a small share of total sawn wood production, this price deviation observed in Table A1 is not likely to introduce any considerable model biases.

Due to unobserved by-product demand in SFSTM II, forest industry by-product prices are lower in the calibrated scenario, compared to observed prices. However, since all by-product prices are lower, and previous scenario analyses using SFSTM II show that by-product prices rise as expected when demand pressure increases, there is no reason to suspect structural biases caused by the initial price deviation. For a more extended discussion on this topic, a more detailed description of the model calibration, as well as a discussion on data source uncertainties (harvesting levels, errors in the actual reported prices, and errors in the imported volumes) the reader is referred to $[13,30,53]$.

\section{References}

[1] H. Thunman, C. Gustavsson, A. Larsson, I. Gunnarsson, F. Tengberg, Economic assessment of advanced biofuel production via gasification using cost data from the GoBiGas plant, Energy Sci. Eng. 7 (2019) 217-229, https://doi.org/10.1002/ ese3.271.

[2] J.M. Ahlström, K. Pettersson, E. Wetterlund, S. Harvey, Value chains for integrated production of liquefied bio-SNG at sawmill sites - techno-economic and carbon footprint evaluation, Appl. Energy 206 (2017) 1590-1608, https://doi.org/ 10.1016/j.apenergy.2017.09.104.

[3] S. Mesfun, J.-O. Anderson, K. Umeki, A. Toffolo, Integrated SNG production in a typical nordic sawmill, Energies 9 (2016) 333, https://doi.org/10.3390/ en9050333.
[4] K. Pettersson, E. Wetterlund, D. Athanassiadis, R. Lundmark, C. Ehn, J. Lundgren, $\mathrm{N}$. Berglin, Integration of next-generation biofuel production in the Swedish forest industry - a geographically explicit approach, Appl. Energy 154 (2015) 317-332, https://doi.org/10.1016/j.apenergy.2015.04.041.

[5] I. Hannula, Making sense of cost and performance estimates for thermochemical biofuel plants. Tcbiomass2017 Tech. Program, Gas Technology Institute, Chicago, 2017.

[6] A. Näyhä, H.-L. Pesonen, Strategic change in the forest industry towards the biorefining business, Technol. Forecast. Soc. Change 81 (2014) 259-271, https:// doi.org/10.1016/j.techfore.2013.04.014.

[7] European Commission, K. Maniatis, I. Landälv, L. Waldheim, E. van den Heuvel, S. Kalligeros, Directorate general for mobility and transport. Building up the Future, Technology Status and Reliability of the Value Chains Sub Group on Advanced Biofuels: Sustainable Transport Forum, 2018. 
[8] E. Gnansounou, A. Dauriat, Techno-economic analysis of lignocellulosic ethanol: a review, Bioresour. Technol. 101 (2010) 4980-4991, https://doi.org/10.1016/j. biortech.2010.02.009.

[9] P. Peck, S. Grönkvist, J. Hansson, T. Lönnqvist, Y. Voytenko, Systemic Constraints and Drivers for Production of Forest-Derived Transport Biofuels in Sweden-Part A: Report, F3-The Swedish Knowledge Centre for Renewable Transportation Fuels, Göteborg, Sweden, 2016.

[10] A.M.I. Kallio, R. Chudy, B. Solberg, Prospects for producing liquid wood-based biofuels and impacts in the wood using sectors in Europe, Biomass Bioenergy 108 (2018) 415-425, https://doi.org/10.1016/j.biombioe.2017.11.022.

[11] E.O. Jåstad, T.F. Bolkesjø, E. Trømborg, P.K. Rørstad, Large-scale forest-based biofuel production in the Nordic forest sector: effects on the economics of forestry and forest industries, Energy Convers. Manag. 184 (2019) 374-388, https://doi. org/10.1016/j.enconman.2019.01.065.

[12] W.F. Mustapha, T.F. Bolkesjø, T. Martinsen, E. Trømborg, Techno-economic comparison of promising biofuel conversion pathways in a Nordic context - effects of feedstock costs and technology learning, Energy Convers. Manag. 149 (2017) 368-380, https://doi.org/10.1016/j.enconman.2017.07.004.

[13] E. Bryngemark, Second generation biofuels and the competition for forest raw materials: a partial equilibrium analysis of Sweden, For. Policy Econ 109 (2019) 102022, https://doi.org/10.1016/j.forpol.2019.102022.

[14] R.P. Chudy, H.K. Sjølie, G.S. Latta, B. Solberg, Effects on forest products markets of second-generation biofuel production based on biomass from boreal forests: a case study from Norway, Scand. J. For. Res. (2019) 1-23, https://doi.org/10.1080/ 02827581.2019.1578403.

[15] F. Mafakheri, F. Nasiri, Modeling of biomass-to-energy supply chain operations: applications, challenges and research directions, Energy Pol. 67 (2014) 116-126, https://doi.org/10.1016/j.enpol.2013.11.071.

[16] D. Yue, F. You, S.W. Snyder, Biomass-to-bioenergy and biofuel supply chain optimization: overview, key issues and challenges, Comput. Chem. Eng. 66 (2014) 36-56, https://doi.org/10.1016/j.compchemeng.2013.11.016.

[17] A. Zamboni, N. Shah, F. Bezzo, Spatially explicit static model for the strategic design of future bioethanol production systems. 1. Cost minimization, Energy Fuels 23 (2009) 5121-5133, https://doi.org/10.1021/ef900456w.

[18] E. Axelsson, S. Harvey, Alliance for Global Sustainability, Pathways to Sustainable European Energy Systems, Scenarios for Assessing Profitability and Carbon Balances of Energy Investments in Industry: AGS Pathways Report 2010:EU1, Alliance for Global Sustainability (AGS), 2010. Göteborg.

[19] X. Zhao, T.R. Brown, W.E. Tyner, Stochastic techno-economic evaluation of cellulosic biofuel pathways, Bioresour. Technol. 198 (2015) 755-763, https://doi. org/10.1016/j.biortech.2015.09.056.

[20] A. Krook-Riekkola, C. Berg, E.O. Ahlgren, P. Söderholm, Challenges in top-down and bottom-up soft-linking: lessons from linking a Swedish energy system model with a CGE model, Energy 141 (2017) 803-817, https://doi.org/10.1016/j. energy.2017.09.107.

[21] K.S. Andersen, L.B. Termansen, M. Gargiulo, B.P. Ó Gallachóirc, Bridging the gap using energy services: demonstrating a novel framework for soft linking top-down and bottom-up models, Energy 169 (2019) 277-293, https://doi.org/10.1016/j. energy.2018.11.153.

[22] P. Fortes, R. Pereira, A. Pereira, J. Seixas, Integrated technological-economic modeling platform for energy and climate policy analysis, Energy 73 (2014) 716-730, https://doi.org/10.1016/j.energy.2014.06.075.

[23] W.F. Mustapha, J.G. Kirkerud, T.F. Bolkesjø, E. Trømborg, Large-scale forest-based biofuels production: impacts on the Nordic energy sector, Energy Convers. Manag. 187 (2019) 93-102, https://doi.org/10.1016/j.enconman.2019.03.016.

[24] J.-C. Hourcade, M. Jaccard, C. Bataille, F. Ghersi, Hybrid modeling: new answers to old challenges introduction to the special issue of "the energy journal, Energy J. 27 (2006) 1-11.

[25] J. Zetterholm, E. Bryngemark, J. Ahlström, P. Söderholm, S. Harvey, E. Wetterlund, Economic evaluation of large-scale biorefinery deployment: a framework integrating dynamic biomass market and techno-economic models, Sustainability 12 (17) (2020) 7126, https://doi.org/10.3390/su12177126.

[26] I.C. Kemp, Pinch Analysis and Process Integration: a User Guide on Process Integration for the Efficient Use of Energy, second ed., Butterworth-Heinemann, Amsterdam ; Boston, 2007.

[27] B. Linnhoff, E. Hindmarsh, The pinch design method for heat exchanger networks, Chem. Eng. Sci. 38 (1983) 745-763, https://doi.org/10.1016/0009-2509(83) 80185-7.

[28] E. Wetterlund, K. Pettersson, R. Lundmark, J. Lundgren, D. Athanassiadis, J. Mossberg, J. Thorén, A. von Schenk, N. Berglin, Optimal Localisation of Next Generation Biofuel Production in Sweden - Part II, f3 The Swedish Knowledge Centre for Renewable Transportation Fuels, Sweden, 2013. www.f3.com.

[29] D. Lestander, Competition for Forest Fuels in Sweden - Exploring the Possibilities of Modeling Forest Fuel Markets in a Regional Partial Equilibrium Framework, Masters Thesis, Swedish University of Agricultural Sciences, 2011.

[30] M. Carlsson, Bioenergy from the Swedish Forest Sector a Partial Equilibrium Analysis of Supply Costs and Implications for the Forest Product Markets, Dept. of Economics, Swedish University of Agricultural Sciences, Uppsala, 2012 accessed, http://urn.kb.se/resolve?urn=urn:nbn:se:slu:epsilon-e-650. (Accessed 20 May 2019).
[31] EU 10308/18, Proposal for a Directive of the European Parliament and of the Council on the Promotion of the Use of Energy from Renewable Sources - Analysis of the Final Compromise Text with a View to Agreement, Council of the European Union, Brussels, 2018.

[32] ECB, ECB euro reference exchange rate: Swedish krona (SEK), Eur. Cent. Bank., 2020 accessed, https://www.ecb.europa.eu/stats/policy_and_exchange_rates/eur o_reference_exchange_rates/html/eurofxref-graph-sek.en.html. (Accessed 23 May 2019).

[33] C.E. Cepci, Chemical Engineering, Plant cost index, 2016, 2016.

[34] A. Alamia, H. Thunman, M. Seemann, Process simulation of dual fluidized bed gasifiers using experimental data, Energy Fuels 30 (2016) 4017-4033, https://doi. org/10.1021/acs.energyfuels.6b00122.

[35] S. Heyne, H. Thunman, S. Harvey, Exergy-based comparison of indirect and direct biomass gasification technologies within the framework of bio-SNG production, Biomass Convers. Biorefinery. 3 (2013) 337-352, https://doi.org/10.1007/ s13399-013-0079-1.

[36] M. Morandin, A. Toffolo, A. Lazzaretto, F. Maréchal, A.V. Ensinas, S.A. Nebra, Synthesis and parameter optimization of a combined sugar and ethanol production process integrated with a CHP system, Energy 36 (2011) 3675-3690, https://doi. org/10.1016/j.energy.2010.10.063.

[37] J.-O. Anderson, A. Toffolo, Improving energy efficiency of sawmill industrial sites by integration with pellet and CHP plants, Appl. Energy 111 (2013) 791-800, https://doi.org/10.1016/j.apenergy.2013.05.066.

[38] SFIF, Database of Member Companies, Swedish Forest Industries Federation, 2015 updated November 2015), August 2012.

[39] B.-O. Danielsson, Uppskattning Av Sågverkens Produktion Av Trädbränslen Inom Mål 1-området I Dalarna-Gävleborg (Transl. Estimate of Sawmill Production of Wood Fuels in Dalarna-Gävleborg), GDE-Net, 2003.

[40] R. Wiberg, M. Forslund, Energiforbrukning I Massa- Och Pappersindustrin 2011, Skogsindustrierna, \AAF, 2012.

[41] Swedish Forest Agency, Rundvirkes- Och Skogsbränslebalanser För År 2013 - SKA 15 (Swedish), Skogsstyrelsen, 2015.

[42] R. Lundmark, D. Athanassiadis, E. Wetterlund, Supply assessment of forest biomass - a bottom-up approach for Sweden, Biomass Bioenergy 75 (2015) 213-226, https://doi.org/10.1016/j.biombioe.2015.02.022.

[43] S. de Jong, R. Hoefnagels, E. Wetterlund, K. Pettersson, A. Faaij, M. Junginger, Cost optimization of biofuel production - the impact of scale, integration, transport and supply chain configurations, Appl. Energy 195 (2017) 1055-1070, https://doi.org/ 10.1016/j.apenergy.2017.03.109.

[44] SFA, Prices on Roundwood in, Sveriges Officiella Statistik, 2017 [Rundvirkespriser 2017, in swedish].

[45] SFA, Bruttoavverkning (Transl. Gross Harvest), Milj. M3 Efter Region, Swedish Forest Agency, Skogsstyrelsen, 2018. https://www.skogsstyrelsen.se/statistik/stat istikdatabas.

[46] FAO Statistics, The Food and Agriculture Organization, FAO, 2018. http://www.fa o.org/faostat/en/.

[47] Nordpool, Historical Market Data - Elspot Prices 2016, 2018 accessed, htt p://www.nordpoolspot.com/historical-market-data/. (Accessed 23 May 2019).

[48] SCB, Energy Prices on Natural Gas and Electricity, Statistics Sweden, 2019. Prices on electricity for industrial consumers 2007-, https://www.scb.se/en/finding-st atistics/statistics-by-subject-area/energy/price-trends-in-the-energy-sect or/energy-prices-on-natural-gas-and-electricity/.

[49] Swedish Energy Agency, Wood Fuel- and Peat Prices, Statistics Sweden Eskilstuna, 2016.

[50] Swedish Pellet Association, Statistikrapport (Statistical Report), Linköping, 2017. http://pelletsforbundet.se/wp-content/uploads/2014/07/StatistikRAPPORT-1 -2017.pdf.

[51] European Pellet Council, European Wood Pellet Consumption, 2018.

[52] WeCalc, WeCalc - Räkna På Skogsbränsle (Transl. Calculate Wood Fuel), 2019 (accessed March 27, 2019), https://www.skogforsk.se:443/produkter-och-evenem ang/verktyg/wecalc/.

[53] E. Bryngemark, The Competition for Forest Raw Materials in the Presence of Increased Bioenergy Demand : Partial Equilibrium Analysis of the Swedish Case, Licentiate, 2019 accessed, http://urn.kb.se/resolve?urn=urn:nbn:se:ltu: diva-72540. (Accessed 20 May 2019).

[54] SDC, Skogsindustrins Virkesförbrukning Samt Produktion Av Skogsprodukter 2011-2016, SDC/VMU, Sundsvall, 2017.

[55] Swedish District Heating Association, Statistics over Fuels and Deliveries in Swedish District Heating Systems 2009-, 2018. https://www.energiforetagen.se/ statistik/fjarrvarmestatistik/tillford-energi/.

[56] Swedish Energy Agency, Drivmedel 2018 - Redovisning Av Raporterade Uppgifter Enligt Drivmedelslagen, Hållbarhetslagen och Reduktionsplikten, Swedish Energy Agency, 2019.

[57] J.M. Ahlström, J. Zetterholm, K. Pettersson, S. Harvey, E. Wetterlund, Economic potential for substitution of fossil fuels with liquefied biomethane in Swedish iron and steel industry - synergy and competition with other sectors, Energy Convers. Manag. 209 (2020) 112641, https://doi.org/10.1016/j.enconman.2020.112641.

[58] European Commission, Quarterly Report on European Gas Markets, DirectorateGeneral for Energy, Market Observatory for Energy, 2019. 